The use of narrative elements in the context of migration theme and intercultural sensitivity in 1llustrated children's books / E. İnal (pp. 166-173)

\title{
08. Resimli çocuk kitaplarında göç teması ve kültürlerarası duyarlılık bağlamında anlatı unsurlarının kullanımı*
}

Ezgi İNAL ${ }^{1}$

APA: İnal, E. (2021). Resimli çocuk kitaplarında göç teması ve kültürlerarası duyarlılık bağlamında anlatı unsurlarının kullanımı. RumeliDE Dil ve Edebiyat Araştırmaları Dergisi, (Ö9), 166-173. DOI: 10.29000/rumelide.984740.

$\ddot{O} z$

Resimli çocuk kitapları, hemen her yaştan çocuğun dil gelişiminde önemli bir yere sahiptir. Özellikle erken çocukluk dönemi olarak da adlandırılan okul öncesi dönemde yararlanılan resimli çocuk kitapları, çocukların bilişsel ve duygusal gelişimleri için okullarda, okul sonrası etüt merkezlerinde, çocuk atölyelerinde ya da ev gibi çeşitli ortamlarda kullanılabilmektedir. 21. yüzyıl çocuklarının sıklıkla karşılaştıkları bir kavram olarak göç, bugün resimli çocuk kitaplarında görülmektedir. Çocukların anlam evreninde doğal bir akışta kendine yer bulan göç kavramının resimli çocuk kitaplarında nasıl ele alındığı ve hangi çerçevelerde sunulduğu önem arz etmektedir. Çünkü bu kitapların çocukların bilişsel, duygusal ve sosyal gelişimlerine katkı sunmakla beraber kültürlerarası duyarlılı̆̆ını artırması öngörülmektedir. Bu bağlamda resimli çocuk kitaplarının ele aldığı unsurları özellikle bilişsel ve duygusal gelişimin kritik dönemlerini yaşayan erken çocukluk dönemindeki çocuklara anlatı çerçevesinde nasıl bir dille aktardığının tespiti, bu çalışmanın temel amacıdır. Bu kapsamda çalışma, nitel araştırma modeliyle yapılandırılarak 9 farklı yazar tarafından kaleme alınmış resimli çocuk kitabı, göç ve kültürlerarası duyarlılık çerçevesinde anlatıdaki metinsellik ölçütleri ve sunumu bakımından incelenmiştir. Bu kapsamda anlatıcıların genellikle kahraman anlatıcı olarak eşit cinsiyet rollerine sahip oldukları, "gece, korku, veda, çanta/bavul, dalga, tekne/bot, umut, bomba, savaş, deniz feneri, sıralanmış insanlar, dil" metaforlarının/betimlemelerinin sıklıkla kullanıldığı, incelenen resimli çocuk kitaplarının metinsellik ölçütlerine büyük oranda uygun oldukları tespit edilmiştir.

Anahtar kelimeler: Resimli çocuk kitapları, göç, dil, anlatı

\section{The use of narrative elements in the context of migration theme and intercultural sensitivity in 1llustrated children's books}

\begin{abstract}
Picture books for children have an important place in the language development of children of almost all ages. Illustrated children's books are especially used in the pre-school period, which is also called early childhood, can be used in schools, after-school study centers, children's workshops or in various environments such as home for the cognitive and emotional development of children. Migration, as a concept frequently encountered by 21st century children, is seen in illustrated children's books today. It is important how the concept of migration, which finds its place in a natural flow in the meaning universe of children, is handled in illustrated children's books and in which
\end{abstract}

RUMELISE2021'de sunulan bildirinin genişletilmiş halidir.

Öğr. Gör., İstanbul Aydın Üniversitesi, Eğitim Fakültesi, TÖMER (İstanbul, Türkiye), ezgiinal1@aydin.edu.tr, ORCID ID: 0000-0002-1573-9401 [Araştırma makalesi, Makale kayıt tarihi: 26.07.2021-kabul tarihi: 20.08.2021; DOI: 10.29000/rumelide.984740]

Adres
RumeliDE Dil ve Edebiyat Araşturmaları Dergisi Osmanağa Mahallesi, Mürver Çiçeği Sokak, No:14/8 Kadıköy - İSTANBUL / TÜRKIYE 34714 e-posta: editor@rumelide.com tel: +90 $5057958124,+902167730616$

Address

RumeliDE Journal of Language and Literature Studies Osmanağa Mahallesi, Mürver Çiçeği Sokak, No:14/8

Kadıköy - ISTANBUL / TURKEY 34714

e-mail: editor@rumelide.com,

phone: +90 5057958124 , +90 2167730616 
frameworks it is presented. Because these books are expected to contribute to the cognitive, emotional and social development of children and increase their intercultural sensitivity. In this context, the main purpose of this study is to determine the language that illustrated children's books deal with, especially to children in early childhood, who experience critical periods of cognitive and emotional development, within the framework of narrative. Within the context, the study was structured with a qualitative research model and the picture book written by 9 different authors was examined in terms of textuality criteria and presentation in the narrative within the framework of migration and intercultural sensitivity. It is clearly seen in these book that narrators generally have equal gender roles as heroic narrators, metaphors/descriptions of "night, fear, farewell, bag/suitcase, wave, boat, hope, bomb, war, lighthouse, lined up people, language" are frequently used, It has been determined that the illustrated children's books examined are largely suitable for the textuality criteria.

Keywords: Illustrated children's books, migration, language, narrative

\section{Giriş}

Resimli çocuk kitapları daha çok çocuk grupları için tercih edilmekle beraber yalnızca belirli yaş gruplarına yönelik olarak hazırlanmış araçlar değil, yetişkinler de dahil olmak üzere bütün yaş gruplarında uygulanacak etkinliklerin ve etkinliklerle öğrenmenin bir parçasıdır. Resimli çocuk kitapları, örneğin drama gibi alanlarda bütün yaş gruplarına yönelik çalışmalarda kullanılabilmektedir (Yıldırım, Aykaç ve Okçu, 2019; Yıldırım ve Aykaç, 2020). Bir başka örnekte ise Temizyürek (2003) Türkçe öğretiminde çocuk edebiyatı ürünlerinden yararlanmanın önemini vurgulamıştır. Disiplinlerarası çerçevede ise Bersh (2013) çalışmasında göç ve göçmenlik konularına ilkokul ve ortaokul müfredatlarında yer verirken resimli kitaplardan yararlanmanın öneminin altını çizer.

21. yüzyıl çocuklarının sıklıkla karşılaştıkları bir kavram olarak göç, bugün resimli çocuk kitaplarında sıklıkla görülmektedir. Çocukların anlam evreninde doğal bir akışta kendine yer bulan göç kavramının resimli çocuk kitaplarında hem görsel hem de yazınsal olarak yer alması nitelikli çalışmaların gerekliliğini artırmaktadır. Çünkü bir yönüyle bu kitaplar toplumsal uyumun da sağlayıcısıdır ve ev ortamında olduğu gibi sınıf ortamında da gerçekleri tasvir eden metinlerin öğretmen tarafından paylaşılması (Rodriguez, Gonzalez ve Rojas, 2020) oldukça değerlidir.

Kültürlerarasılık ve buna bağlı olarak düşünüldüğünde kültürlerarası yeti, bireyin kendi kültürü dışındaki insanlarla etkili iletişim kurma olarak tanımlanmaktadır (Byram ve Masuhara, 2020: 143). Bu kapsamda ortaya çıkacak kültürlerarası duyarlılık da önemli bir gereklilik halini almaktadır. Bu duyarlılık belirli bir çerçevede gelişmektedir (Hammer, Bennett ve Wiseman, 2003: 424):

RumeliDE Dil ve Edebiyat Araştırmaları Dergisi Osmanağa Mahallesi, Mürver Çiçeği Sokak, No:14/8 Kadıköy - ISTANBUL / TÜRKIYE 34714 e-posta: editor@rumelide.com tel: +90 $5057958124,+902167730616$
Address

RumeliDE Journal of Language and Literature Studies Osmanağa Mahallesi, Mürver Çiçeği Sokak, No:14/8

Kadıköy - ISTANBUL / TURKEY 34714

e-mail: editor@rumelide.com,

phone: +90 $5057958124,+902167730616$ 
The use of narrative elements in the context of migration theme and intercultural sensitivity in illustrated children's books / E. İnal (pp. 166-173)

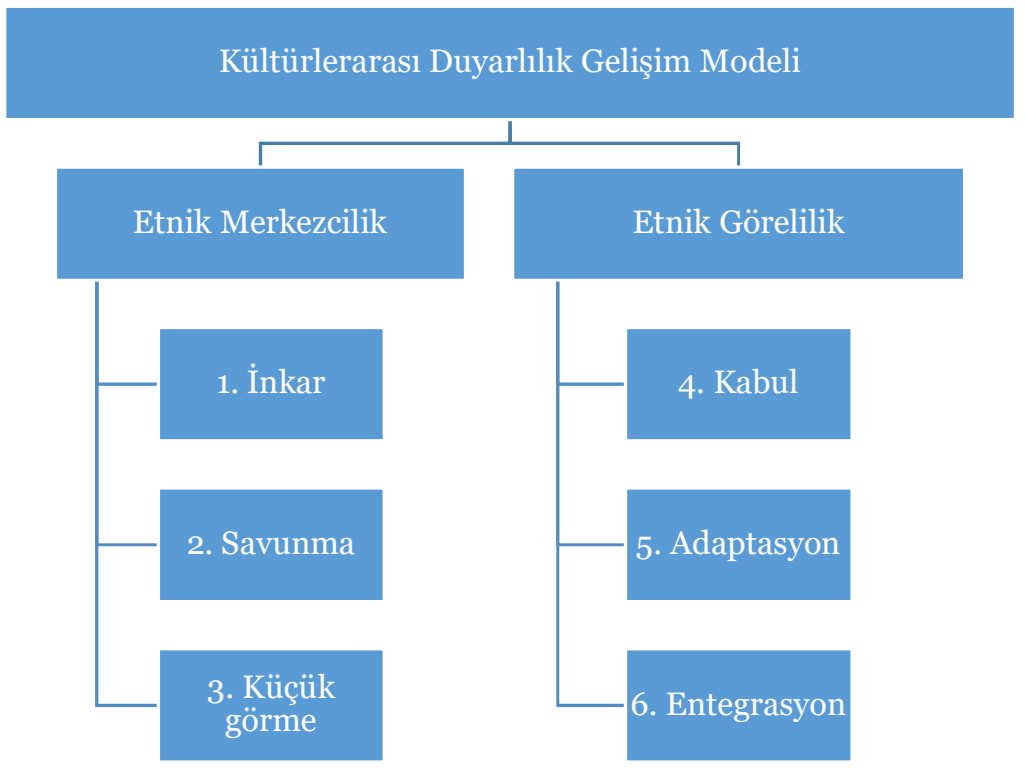

Şekil 1. Kültürlerarası Duyarlılık Gelişim Modeli

Şekil 1 incelendiğinde kültürlerarası duyarlılık gelişim modelinde altı kritik sürecin yer aldığı görülmektedir. Bu nedenle kültürlerarası duyarlılı̆̆ın hızlı ve sağlıklı gelişmesine yönelik üretilen bütün ürünlerin titizlikle hazırlanması gerekmektedir. Bu çerçevede okuma metinleri; pek çok sosyal konuyu özellikle çocuk gruplarında çocuklara anlatılması zor olan göç, savaş, doğal afetler gibi süreçleri zengin metaforlarla ve doğru bir kurgu ile aktarabilmeleri bakımından oldukça değerlidir. Dahası çocuklara bu konuların nasıl bir kurguda sunulduğu kritik bir mesele olarak karşımıza çıkmaktadır. Bu çalışmanın amacı göç ve kültürlerarasılık süreçlerinin resimli çocuk kitaplarında nasıl ele alındığını ve çocuklar için nasıl sunulduğunu incelemektir. Buradan hareketle çalışma alt problemlerinde ise göç ve kültürlerarasılık bağlamında konu, anlatıcı ve kahraman özelliklerine; görsel ve yazınsal metafor/betimlemelerine ve metinsellik ölçütlerine değinilecektir.

\section{Yöntem}

Çalışma nitel araştırma olarak tasarlanmıştır. Verilerin toplanmasında doküman analizi kullanılmıştır. Doküman incelemesi, en genel çerçevede araştırma içeriğine uygun olarak toplanan kaynakların analizini ifade eder (Yıldırım ve Şimşek, 2011). 9 farklı resimli çocuk kitabından elde edilen verilerin analizinde ise içerik analizi kullanılmıştır. İçerik analizi söz konusu materyallerin içerdiği mesajı, anlam ve/veya dilbilgisi açısından nesnel ve sistematik olarak sınıflandırma, sayılara dönüştürme ve bunlara bağlı çıkarımda bulunma (Tavşancıl ve Aslan, 2001: 22) olarak tanımlandığından bu çalışmada göç ve kültürlerarası duyarlılık temasına uygun olarak belirlenen resimli çocuk kitaplarının içeriği analiz edilmiştir. Bu kapsamda araştırmacı tarafından kitaplarda öne çıkan konu, görsel ve yazınsal metaforların/betimlemelerin, anlatıcı ve kahramanların kategorilere ayrılarak analizinin yanı sıra kitaplardaki anlatılar Beaugrande ve Dressler (1981)'in metinsellik ölçütleri bakımından da incelenmiş içerik özellikleri bakımından çıkarımlarda bulunulmuştur. Çalışma bütüncül bir bakış açısıyla gerçekleştirilmiştir. Odağında erken çocukluk dönemi ile göç ve kültürlerarası duyarlılık konularına yer verilmiş olan kitaplar, rastlantısal olarak seçilmiştir. Halihazırda basılmış ve bu özellikleri barındıran sınırlı sayıda kitap olması araştırmanın örneklemini doğal olarak belirlemiştir.

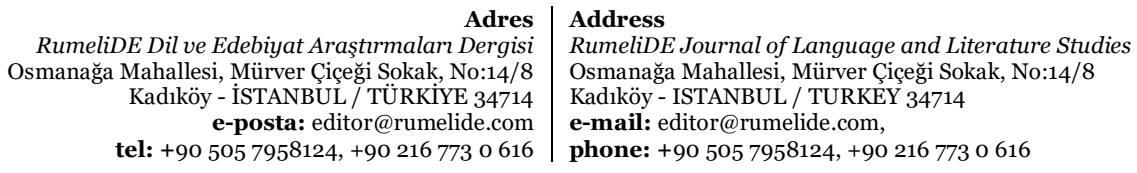


Bulgular

a. Öne çıkan konu, anlatıcı, kahraman

Tablo 1'de incelenen resimli çocuk kitaplarında öne çıkan konu, anlatıcı ve kahraman özelliklerine yer verilmiştir. Bu unsurlar, metnin okuyucuyla buluşmasını sağlayan aracılar olarak tanımlanabilir.

Tablo 1. İncelenen resimli çocuk kitaplarında öne çıkan konu, anlatıcı, kahraman özellikleri

\begin{tabular}{|c|c|c|c|c|}
\hline & Kitabin Ad 1 & Öne Çıkan Konu & Anlatic1 & Kahraman \\
\hline 1 & $\begin{array}{l}\text { Benim Adım Mülteci } \\
\text { Değil }\end{array}$ & Yolculuk ve kültürlerarası duyarlılık & Kahraman & Erkek çocuk \\
\hline 2 & Bot Hikayesi & Yolculuk & Kahraman & Kız Çocuk \\
\hline 3 & Dönme Dolap & Yolculuk ve Umut & Yazar & $\begin{array}{l}\text { Kiz çocuk ve erkek } \\
\text { çocuk }\end{array}$ \\
\hline 4 & $\begin{array}{l}\text { Evinden Uzakta } \\
\text { (Mülteci) }\end{array}$ & Yolculuk ve kültürlerarası duyarlılık & Kahraman & Kız çocuk \\
\hline 5 & Herkes Burada & $\begin{array}{l}\text { Yolculuk, Kültürlerarası Duyarlılık, Farklı } \\
\text { Yaşam Deneyimleri }\end{array}$ & Yazar & $\begin{array}{l}\text { Birden fazla } \\
\text { kahraman }\end{array}$ \\
\hline 6 & Hoş Geldiniz & $\begin{array}{l}\text { Kültürlerarası Duyarlılık, Göç nedeni olarak } \\
\text { doğa }\end{array}$ & Kahraman & Kutup Ay1sı \\
\hline 7 & Mervan'ın Yolculuğu & Yolculuk ve Umut & Kahraman & Erkek Çocuk \\
\hline 8 & Taştan Adımlar & Yolculuk ve kültürlerarası duyarlılık & Kahraman & Kiz çocuk \\
\hline 9 & Yolculuk & Tehlike, belirsizlik & Kahraman & Kiz çocuk \\
\hline
\end{tabular}

Araştırmanın odağında yer alan resimli çocuk kitapları incelendiğinde kitaplardan 7'sinin doğrudan göç yolculuğunu konu edindiği; bu metinlerden yalnızca 2 tanesinde anlatıcının yazar olduğu; başkahramanlarının ise 2' sinin erkek çocuk, 2'sinin kız çocuk, 1'isinin hem kız hem erkek çocuk, 1'isinin hayvan olduğu, 1 kitapta ise birden fazla anlatıcı olduğu tespit edilmiştir. Bu durum, göç ve kültürlerarası duyarlılık kapsamında ele alınan resimli çocuk kitaplarında kahramanların toplumsal cinsiyet bakımından dengeli bir dağılıma sahip olduğunun göstergesidir. Nitekim bu konu, her yaştan ve her cinsiyetten çocuğa yönelik hassas bir konu olarak değerlendirilebileceğinden bu rollerin sosyal iletişime katkı sağlayıcı ve işlevsel unsurlar olarak mevcut sunumlarıyla önemli bir yere sahip oldukları ifade edilebilir.

\section{b. Görsel ve yazınsal metaforlar/betimlemeler}

Tablo 2' de söz konusu resimli çocuk kitaplarında yer alan göçü ifade eden metaforlar, yazınsal ve görsel betimlemeler yer almaktadır.

Tablo 2. İncelenen resimli çocuk kitaplarında yer alan görsel ve yazınsal metaforlar/betimlemeler

Kitabın Adı Öne çıan metaforlar/betimlemeler

1 Benim Adım "çanta, veda, yıkılmış evler, çadır, dil, sıradaki insanlar" Mülteci Değil

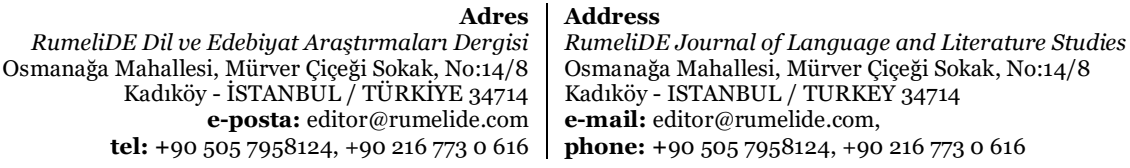


The use of narrative elements in the context of migration theme and intercultural sensitivity in 1llustrated children's books / E. İnal (pp. 166-173)

2 Bot Hikayesi

3 Dönme Dolap

4 Evinden Uzakta (Mülteci)

5 Herkes Burada

6 Hoş Geldiniz

7 Mervan'in Yolculuğu

8 Taştan Adımlar

9 Yolculuk "fincan, battaniye, deniz feneri, deniz, gece, valiz, dalgalar, sıra sıra insanlar, çadırlar, ay, yıldızlar, küçük bir çocuğun bottan limandaki bir başka kişiye uzatıldığı an"

"veda, yıkılmış bir yer, ana cadde, şekerci, yağmur, nehir, aynı dönme dolapta olmak."

"savaş, yalnızlık, kargalar, ateş edilmiş duvarlar, deniz, bot, beyaz güvercin"

“uzak, korkmak, gece, tekne, bomba, anadili, özel günler"

"beklenmedik bir durum, karanlık, fırtına, dalga, farklılıkların kabul görmemesi, empati"

“Çanta, yürümek, belirsizlik, yamalı elbiseler, dua kitabı, defter, kalem, fotoğraf, yorgan, öksüz olmak, gece, umut, soğuk, karanlık, ayak, sınır, dil, hikâye"

"özgürlük, savaş, ölüm, bomba, deniz, dalga, tekne, yürümek, paylaşmak, yeni koku"

"savaş, karanlık, ölüm, kaçmak, bavullar, vedalaşmak, gece, duvar, tanımadıkları bir adama para vermek, sınır, sıkış sıkış tekne, deniz feneri, tren, kuşlar"

Kitaplar incelendiğinde "gece, korku, veda, çanta/bavul, dalga, tekne/bot, umut, bomba, savaş, deniz feneri, sıralanmış insanlar, dil” metaforlarının/betimlemelerinin sıklıkla kullanıldı̆̆ı tespit edilmiştir. Buradan hareketle resimli çocuk kitaplarında betimlenen göç durumlarının bir ülkeden savaş nedeniyle başka bir ülkeye kaçmak olarak işlendiğini, bu çerçevede birinci tabloda yoğun olarak yer alan "yolculuk" konusunun esasında ürpertici, belirsiz ama umut dolu bir yolculuk olarak gösterildiğini söylemek mümkündür. Tespit edilen diğer metaforların ise anlatıdaki kırılma noktalarını zenginleştirici ve tamamlayıcı özelliklere sahip olduğu görülmüştür.

\section{c. Metinsellik unsuları}

Dilsel özelliklerin metin özelliklerini kazanması ve insanlarla iletişim oluşturması için gerekli bazı kurucu özellikler bulunmaktadır (Beaugrande ve Dressler, 1981: 3). Bu çerçevede bağdaşıklık, sözcükler ve cümleler arası uyum, anlamlılık durumlarını; tutarlılık metin içinde yer alan kavramların anlam bağını; amaçlılık yazar tarafından metinde ortaya konulan mesajı ya da mesaj dizisini; kabul edilebilirlik yazarın amacı ile okuyucu kitlesinin benzer bir anlam dairesinde oluşunu; bilgilendiricilik metinde yer alan bilgiler arası ilişki ve dengeyi; duruma uygunluk metin türü-konu ve okuyucu kitlesi arasındaki uyumu; metinlerarasılık ise farklı metinler arasındaki ilişkiyi bir başka ifade ile bir metnin

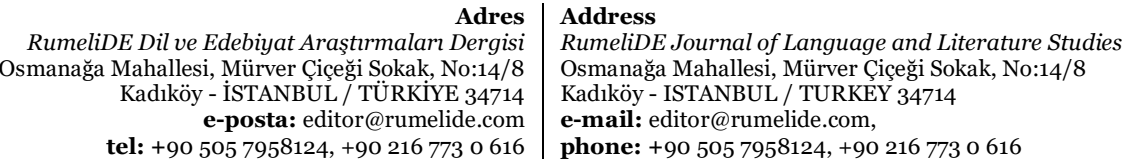


ortaya çıkarken bir başka metinden soyutlanmaksızın metnin var oluşsal durumunu ifade eden kavramlardır.

Tablo 3. İncelenen resimli çocuk kitaplarında yer alan metinsellik unsurları

\begin{tabular}{|c|c|c|c|c|c|c|c|c|c|}
\hline & 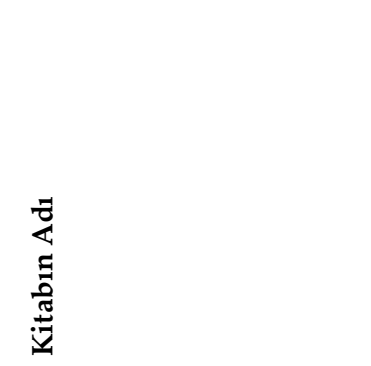 & 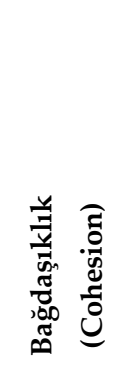 & 菉 & 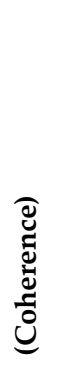 & 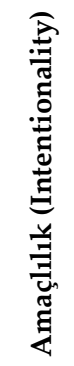 & 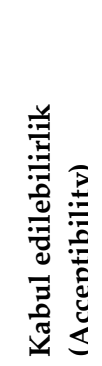 & 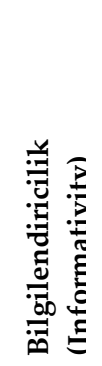 & 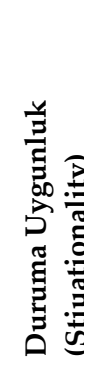 & 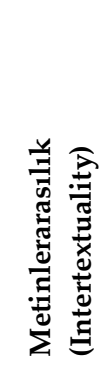 \\
\hline 1 & Benim Adım Mülteci Değil & + & + & & + & + & + & + & + \\
\hline 2 & Bot Hikayesi & + & + & & + & + & + & + & + \\
\hline 3 & Dönme Dolap & + & + & & + & + & + & + & + \\
\hline 4 & Evinden Uzakta (Mülteci) & + & + & & + & - & + & - & + \\
\hline 5 & Herkes Burada & + & + & & + & + & + & + & + \\
\hline 6 & Hoş Geldiniz & + & + & & + & + & + & + & + \\
\hline 7 & Mervan'ın Yolculuğu & + & + & & + & - & + & - & + \\
\hline 8 & Taştan Adımlar & + & + & & + & + & + & + & + \\
\hline 9 & Yolculuk & + & + & & - & - & - & - & + \\
\hline
\end{tabular}

İncelenen resimli çocuk kitaplarından altısının metinsellik unsurlarının (Beaugrande ve Dressler, 1981) tamamını karşıladığı görülmüş̧; ikisinin kabul edilebilirlik ve duruma uygunluk ilkeleriyle uygun olmadığı; birinin ise çocuklara göç olgusunu anlatabilmeye yönelik olarak amaçlılık, kabul edilebilirlik, bilgilendiricilik, duruma uygunluk ilkelerine uygun olmadığı tespit edilmiştir. Ayrıca her görsel bir metindir. Bu kapsamda Beaugrande ve Dressler (1981)'e göre incelenen resimli çocuk kitaplarının metinlerarasılık kurucu özelliğine uygun olduğu söylenebilir.

\section{Tartışma ve sonuç}

Göç; politik ve ekonomik nedenlerin yanında sosyal, kültürel vd. nedenlerle ortaya çıkabilen karmaşık bir yapıya sahiptir (Şahan, 2018: 10). Resimli çocuk kitaplarında yer alan böylesi önemli ve özel konuların çocukların zihninde boşluklara neden olmayacak şekilde iyi kurgulanarak ifade edilmesi önemlidir. Çünkü göç durumu hem göç eden hem de göçmenlerle ortak yaşam alanı paylaşan ve mevcut kültürde o kültürün bir parçası olarak yaşamını sürdüren diğer çocuklar için bir yeniliktir ve doğrudan gelişimi etkileyen önemli bir faktördür (Santrock, 2021: 493-495).

Bu çalışmada göç konusuyla birlikte kültürlerarası duyarlılık konusuna oldukça az yer verildiği, kültürlerararası duyarlılı̆̆ın umut ve yardım unsurlarıyla bağdaştırılarak sınırlandığı; daha çok göç ve mülteci olma durumunun yarattığı duygulara yer verildiği görülmüştür. Çetinkaya ve Durmaz (2020) çalışmalarında çeviri kitaplar özelinde resimli çocuk kitaplarında genellikle yabancı kültür ögelerinin yer aldığını tespit etmişlerdir. Ancak söz konusu tespit konu göç ve kültürlerarası duyarlılık; buna bağlı

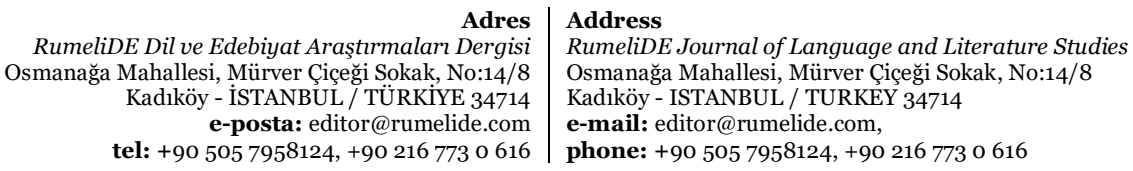


The use of narrative elements in the context of migration theme and intercultural sensitivity in 1llustrated children's books / E. İnal (pp. 166-173)

olarak da evrensel kültür unsurları olduğunda yaptığımız incelemede evrensel unsurlara ve mesajlara yer verildiği görülmekte hatta bazı bölümlerde okuyucunun zihninde, bir başka ifade ile kişisel yaşam tecrübesinde yer alan imgeleri harekete geçirebilecek genel meseleler ön plana çıkmaktadır. Nitekim Hsu (2014) çalışmasında özellikle okul öncesi dönemde kullanılan resimli çocuk kitaplarının çocukların kültürel değerleri ve farklılıkları anlamasında yardımcı olduğundan söz eder. Dolayısıyla resimli çocuk kitaplarının kültürlerarası duyarlılığa katkısı bulunmaktadır. Bu kapsamda gelecekte yapılacak çalışmalar; göçü bütüncül bir bakış açısıyla ele alacak şekilde, toplumsal cinsiyet eşitliği gözetilerek, romantik yaklaşımlardan uzak kapsayıcı bakış açısına uygun gerçekleştirilmelidir.

Yazarların hitap ettikleri öncelikli grubun çocuklar olduğunu göz önünde bulundurmaları hatta hitap ettikleri bir diğer öncelikli kitlenin toplum dilini yeni öğrenen yetişkin göçmenlerin de olduğunu unutmamaları; bu çerçevede bir üslup geliştirmeleri, çizerlerin de görsel anlatı süreçlerini iyi tasarlamaları; yukarıda sözü edilen unsurların çocukların duygu dünyasına hitap eden anlatılarda yer alması gereken "çocuğa görelik" ilkesine uygun içerikler oluşturmaları gerekmektedir.

Göç ve kültürlerarası duyarlılık temalı anlatıları aynı zamanda bu anlatıların öznesi olan çocukların da bir gün okuyacakları unutulmamalıdır.

\section{Kaynakça}

Arias, P. (2018). Mervan’n Yolculuğu (Çev. M. F. Edis). İstanbul: Edam.

Barroux (2017). Hoş Geldiniz (Çev. O. Aydın). İstanbul: SEV.

Beaugrande, R. A.de ve Dressler W. U. (1981). Introducti on to Text Linguistics. Longman: London.

Byran, M. ve Masuhara, H. (2020). Kültürlerarası Yeti. Uygulamah Dilbilim ve Materyal Geliştirme

(Ed. B. Tomlinson, Çev. Ed. N. Yazıcı). Ankara: Nobel yay.

Çetinkaya, F , Durmaz, M . (2020). Çeviri resimli çocuk kitaplarının kültür aktarımı açısından incelenmesi stili. Abant İzzet Baysal Üniversitesi Eğitim Fakültesi Dergisi, 20 (2) , 945-959 . DOI: 10.17240/aibuefd.2020.-567554

Hammer, M. R., Bennett, M. J., \& Wiseman, R. (2003). Measuring intercultural sensitivity: The Intercultural Development Inventory. International Journal of Intercultural Relations, 27(4), 421443 .

Hest, P. (2017). Evinden Uzakta/Mülteci (Çev. Ş. Helvacılar). İstanbul: Gergedan.

Hsu, Y. (2014). Multicultural education for young children-beginning from children's Picture books. International Journal of Educational Planning and Administration, 4(1), 79-84.

Kozikoğlu, T. (2020). Dönme Dolap. İstanbul: Doğan Egmoont.

Maclear, K. (2020). Bot Hikayesi (Çev. Ö. F. Yeni). İstanbul: Albaraka Kültür ve Sanat

Milner, K. (2019). Benim Adım Mülteci Değil (Çev. A. Turhan). İstanbul: Arden.

Rodriguez, Sanjuana C.; Gonzalez, Karina; and Rojas, Carolina (2020) "Immigration Picture Books by \#ownvoices Authors," Georgia Journal of Literacy: 43(2).

Ruurs, M. (2017). Taştan Adımlar Bir Mülteci Ailenin Yolculuğu (Çev. S. Öge). İstanbul: Nesin.

Sanna, F. (2016). Yolculuk (Çev. Z. Sevde). İstanbul: Taze Kitap.

Santrock, J. W. (2021). Çocuk Gelişimi (Çev Ed. Ayşen Güre). Ankara: Nobel)

Şahan, G. (2018). Göçmen Çocukların Eğitimi (Almanya'da Türk Çocukları). Ankara: Anı.

Tavşancıl, E., Aslan, A. E. (2001). Sözel, Yazılı ve Diğer Materyaller İçin İçerik Analizi ve Uygulama Örnekleri (1. Baskı). İstanbul: Epsilon.

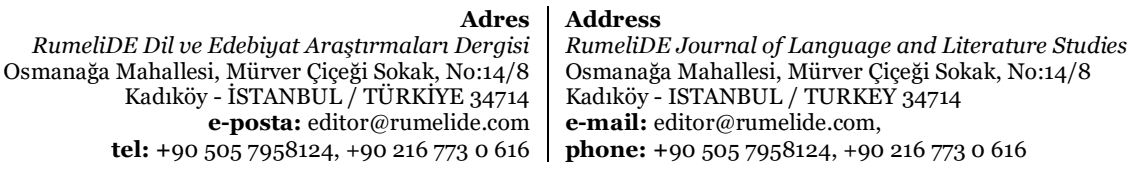


Temizyürek, F. (2003). Türkçe Öğretiminde Çocuk Edebiyatının Önemi. Türklük Bilimi Araşttrmaları Dergisi, 13, 161-167

Tuckermann, A. (2017). Herkes Burada (Çev. U. Önver). İstanbul: Kırmızı Kedi.

Yıldırım, K, Aykaç, N. (2020). Yaratıcı Drama Destekli Resimli Çocuk Kitaplarının Öğretmen Adaylarının Kültürlerarası Duyarlllıklarına Etkisi. Yaratıcı Drama Dergisi, 15(2), 259-274

Yıldırım, K., Aykaç, N. ve Okçu, S. T. (2019). Yaratıcı Drama ve Resimli Çocuk Kitapları: Kültürlerarası Duyarlılığı Geliştirmek İçin Örnek Bir Uygulama. Yaratıcı Drama Dergisi, 14(1), 55-72.

Yıldırım, A., \& Şimşek, H. (2011). Sosyal Bilimlerde Nitel Araştırma Yöntemleri. Ankara: Seçkin Yayınevi.

RumeliDE Dil ve Edebiyat Araştırmaları Dergisi Osmană̆a Mahallesi, Mürver Çiçeği Sokak, No:14/8 Kadıköy - İSTANBUL / TÜRKIYE 34714 e-posta: editor@rumelide.com tel: +90 $5057958124,+902167730616$
Address

RumeliDE Journal of Language and Literature Studies Osmanağa Mahallesi, Mürver Çiçeği Sokak, No:14/8

Kadıköy - ISTANBUL / TURKEY 34714

e-mail: editor@rumelide.com

phone: +90 $5057958124,+902167730616$ 